\title{
The Glass Ceiling Conundrum: Illusory belief or Barriers that impede Women's Career Advancement in the Workplace
}

\begin{abstract}
Given the preponderance of women in the workforce, it remained a puzzle why the entry of women into higher managerial positions remains restricted and why the syndrome of "think manager think male is growing progressively? The objective of this paper is to examine the glass ceiling conundrum with a view of ascertain how it limits women's career advancement in the workplace. Extensive review of literature was presented and discussed. The paper revealed that women are not making it to the very top of their career not as a result of lack of requisite qualifications, and experience etc.; but as a result of factors that are rooted in cultural, societal, organizational, individual and psychological factors that inhibit women career advancement. Against the aforementioned background, the paper concludes that women advance marginally to certain level in corporate executive cadre, before they experience 'glass ceiling' that impedes their prospect of attaining senior executive position. Accordingly, women compared to men represent an insignificant fraction of those in managerial positions due to cultural prejudice, religion convictions, family related issues, individual and organizational influences. Similarly, inadequate opportunity to networks and seek sponsorship limits women progression to top managerial hierarchy. The study recommends the need to articulate policy frameworks that promote strong organizational culture and a more helpful and supportive environment to develop women leadership skills. Similarly, there is need to promote sponsorship for women in a way and manner that safeguard the relationships between sponsors and protégés.
\end{abstract}

Keywords: Glass Ceiling; Women Executives; Gender; Career Advancement; Work Life Balance; Discrimination

Corresponding author: e-mail: abdulrahimajao@yahoo.com

Received 10 August 2016 - Accepted 08 March 2017

This is an Open Access article distributed under the terms of the Creative Commons Attribution-Non-Commercial-No Derivatives License (http://creativecommons.org/licenses/by-nc-nd/4.0/), which permits non-comercial re-use and distribution, provided the original work is properly cited, and is not altered or transformed in any way. 


\section{Introduction}

Despite the progress recorded with the formation of numerous women's movements and amendment to employment polices aiming at strengthening gender equality, women are still struggling to have remarkable representation in top managerial positions (Davidson and Burke, 2012). Obstacles to secure top managerial positions are a global phenomenon where women, compared to men, are extremely concentrated in lower-level and lower-cadre leadership positions (Mohammadkhani and Dariush 2016). According to the report released by The American Association of University Women- AAUW (2016), women have recorded significant improvement in labor participation and some headway in executive positions, but there is stark disparity in women representation in corporate leadership position not only in business, but across unions, religious bodies, academia, the legal occupation and many other institutions.

Glass ceiling (GC) is a phenomenon that portrays the relative disadvantage regarding career opportunities for women, revealing dilemmas that women experience when reaching advance stage of their career (Kolade and Kehinde 2013; Jasielska 2014). Hence, this situation is defined as "ceiling" because there are obstacles in the upward progress and "glass" (apparent) because the restriction is not openly observable and is commonly a workplace ethos that is not formerly written (Hiau 2008). Indeed, the obstacles to women career reveal discrimination and a border line that demarcate how women career progresses compare to their male counterpart. According to Powell and Butterfield (2003), glass ceiling is a form of barrier in the workplace that is so subtle and apparent, yet so tough that it proscribed women and minorities from occupying top position in management hierarchy. In contrast, to recognized barriers to career progression such as inadequate education and lack of requisite work experience, the glass ceiling barriers are less tangible and may be rooted in culture, society, organizational, individual and psychological 
factors that work collectively to obstruct the progression of women to managerial positions (Jain and Mukherji 2010). According to Morgan (2015), the glass ceiling obstacles can be categorized into artificial and natural barriers. In her opinion, artificial barriers can best be comprehended by contrasting with what might be called "natural" barriers founded on educations or career breaks which influenced career progression.

Literally, the representation of the "glass ceiling" suggests the reality of an impervious obstacle that blocks the vertical mobility of women as they rise through corporate ladder (Eagly and Carli 2007). As observed by Morrison, White, and Von-Velsor (1987), the glass ceiling is an obvious hiccup that prevents women from rising beyond certain echelons, simply because they are women. Ridgeway (2001) states that irrespective of the exact mechanism promoting glass ceiling, the phenomenon portray the relative disadvantages women face in securing jobs and promotions in the upper levels of managerial hierarchies. The invisible barriers confronted by women folks, according to Baxter and Erik (2000) are not peculiar to the top cadre position, but also in middle-level management and minorities (people of race, color, and disabilities; etc.).

A report released by International Labor Organization-ILO revealed that between 1995 and 2015, female labor force participation rate diminished from $52.4 \%$ to $49.6 \%$ worldwide. The corresponding figures for men according to the report are $79.9 \%$ and $76.1 \%$, respectively. Thus, women's lesser participation proportions result into declining employment opportunities, with little difference over time, which depressingly upsets women's earning capacity and economic security, thus, women continue to be overrepresented in informal sector and family workers (ILO 2015). As expressed by Meyerson and Fletcher (2000), women at the highest levels of corporate cadres are still rare and very few occupy the uppermost echelons of power. For instance, two-thirds of managerial-rank women at Fortune 1000 firms cluster were below the 
top two steps of leadership levels (Constance, Dawn, and Paul 2006). According to Catalyst (2015), men are much likely than women to be considered for leadership position. Their report further revealed that only five percent of the businesses in the Standard and Poor's 500 index had women Chief Executive Officers in 2015. Statistics released by the Equal Opportunity for Women in the Workplace Agency, revealed that only two of the top 200 enterprises are directed by women, and only four have women Chief Executives (Hiau 2005).

Similarly, available data in developing country like Nigeria reveals a high degree of discrepancy in levels of gender at top management positions. For illustration, in the Nigerian Federal Civil Service, which is the leading employer of labor in the country, $76 \%$ of civil servants are men, and $24 \%$ are women with women holding less than $14 \%$ of the total management level positions in the Nigerian public sector (Goldstar Directories 2007). Similar accounts is reported in Lagos state, which is the Nigeria's largest commercial hub; private sector participation of women as directors and top management were $13.87 \%$ and $13.84 \%$ respectively in 2005 , while $8.14 \%$ and $13.11 \%$ were recorded for women directors and top managers respectively in 2006 , signifying further decline in their representation (Goldstar Directories 2007).

Discrimination in any form is prohibited in the workplace. Yet, discrimination exists in varying nature and dimensions towards women career progression. While there has been some improvement, much remains unchanged. Therefore, advancement of women career continues to be a challenge due to poor organizational support, bias corporate policies and practices, inadequate training opportunities to develop their capabilities, absence of role models and counselors, and cultural beliefs and rules (Kunze 2008). As a result, women required different kind of support to break the glass ceiling that scholars like Lombardo and Meier (2006) and 
Hassim (2009) claimed might be accompanied by unconventional, unpleasant and unanticipated consequences.

Researchers have presented a multiplicity of theories to explain the occurrence of the glass ceiling phenomenon in the workplace. Nonetheless, the conundrum behind this influence is still largely diverse and growing in intensity (George 2003). Although in contrast to what was obtainable some decades back, career women are now building networks that will aid their career progression; however, there is still prevaricated assessment of leadership behavior and capabilities of women (Davidson and Burke 2012). In other words, the myopic conviction that men are well-matched for leadership position seems difficult to challenge (Mordi et al. 2010). The "gentleman's club" promoted by glass ceiling constitute double jeopardy for women; given the fact that women participation in labor market is disproportionate in favor of men, and the few that are employed and possess the requisite qualifications and experience represent a tiny fraction of those in managerial positions (ILO 2015). The erroneous notion that corporate organizations are gender unbiased and ignorance of discrimination in the workplace has further created difficulty in minimizing the obstacles associated with glass ceiling (Kantor 1977). As observes by Adler (1993), corporate organizations have structure and policies that support male socialization, which portrays that they are primarily created and dominated by men. Consequently, men appear to have more disposition and arsenal for organizational politics than women (Kantor 1977).

To date, the glass ceiling constitute a topical challenge and there is abundant evidence that labor market discrimination against women persists, although it is difficult to conclude accurately how much of the disparity in men/women pay and career progression is due to discrimination and how much is connected to differences in choices or preferences between women and men 
(Morgan 2015). One of the main reasons for the aforementioned challenges is that it is difficult to connect glass ceiling conundrum to one domain of knowledge; and more worrisome is the scanty nature of systematic review of literature related to glass ceiling phenomenon (Saul, Ute, and Suncica 2014). Besides, some of these previous studies are patchy and inadequate to build a comprehensive understanding of the glass ceiling and its associated consequences (Jerlando and O'Challagham 2009). As a result, there is need for concerted effort to integrate the existing literature with a view of realigning and crystalizing the operationalization and manifestation of glass ceiling in the workplace. Against the above presentation, the objective of this paper is an attempt to provide a review of the glass ceiling phenomenon as a deceptive belief or oppressive tendency that restricts women's career advancement in the workplace. Specific objectives of this paper are to: (1) evaluate the level of women representation in top managerial hierarchy, (2) identify the barriers that inhibit women career advancement, (3) determine how work-life balance hinders the career prospects of women, (4) examine how old boys' network create discriminatory views for women in the workplace, and (5) assess difference in the level and form of sponsorship for women compared to their male counterparts in the workplace. To achieve the aforementioned research objectives, the paper attempts to answer the following research questions:

1. What is the level of women representation in top managerial hierarchy?

2. What are the barriers that inhibit women career advancement?

3. How does work-life balance hinder the career prospects of women?

4. What is the role of old boys' network in creating discriminatory views for women in the workplace?

5. To what extent do the level and forms of sponsorship for women differ from their male counterparts? 


\section{Theoretical and literature review}

The role congruity theory

The role congruity theory has its origins in social role theory which describes the dissimilar social positions of men and women and how it creates differing gender roles (Eagly, Wood, and Diekman 2000). The role congruity theory was developed by Eagly and Karau (2002) to provide a theoretical foundation toward a better understanding of the dynamics and diverse assessments of women and men in managerial positions. The role congruity theory explains the undesirable appraisals of female executives arising from perceived incongruity between managerial role and feminine character attributed to women (Eagly and Karau 2002). Essentially, role congruity theory is founded on the notion that the impetus to accomplish role congruity is an important element in leadership effectiveness. On this note, women may be subjected to some form of stereotypes that contribute to their under-representation in managerial positions, which may further aggravate how female gender roles are observed as incongruent with the requirements needed for successful leadership (Eagly and Karau 2002). These scholars further maintained that since managerial position has been fundamentally view as male right, there might be perceived incompatibility between the feminine gender roles and leadership roles.

Accordingly, role congruity theory describes how stereotypes and agentic and communal individualities interact to influence women's accomplishment in the work place. Agentic characters refer to some features more frequently attributed to males, which encompasses - selfconfident, controlling, and assertive form of behavior (Eagly and Johannesen-Schmidt 2001). Communal traits on the other hand, consist of characteristics more commonly credited to females, such as interpersonally sensitive and nurturing form of behavior (Eagly and Johannessen-Schmidt 2001). According to this theory, women are perceived less suitable to 
occupy executive positions in organizations compared to men because they lack requisite behavioral characteristics such as articulate and authoritarian tendency required by leaders (Eagly and Karau 2002). Hence, preference is given to men because it is assumed that men are better managers than women; hence the syndrome of 'think manager think male (Schein 2007).

Social role and identity theory

One of the foremost explanations attributed to the 'glass ceiling conundrum' is the 'social role theory' formerly suggested by Eagly in 1987. Accordingly, social role and identity theory suggests that men and women act according to the social roles (e.g. class, gender and race) ascribed to them and which are dictated by the way their genders are stereotyped. According to Eagly (1987), this theory was coined from the division of labor ideologies which echoes a biosocial interaction between male and female physical attributes and social configuration. According to this scholar, social role theory acknowledges that both men and women occupy numerous social roles (i.e. organizational role) which can surpass gender specific roles contingent on the situation. For instance, women are associated with characters such as caring, compassion and attention in their relationships with others (Fondas 1997; Rahim, DixxonOgbechi, and Ighomereho 2013). Although these comportments are not typical of a corporate board room, it does not mean that they cannot be beneficial to the organization (Daily, Dalton, and Albert 2003). In contrast to women, men are perceived as more competitive, autonomous and independent in nature (Rudman and Glick 2001). The aforementioned traits are to some extent the anticipated norms in corporate organization. Thus, the notion of social identity theory in this context explains a deeper motive as to why women to some extent are being underrepresented in leadership position (Singh and Vinnicombe 2004). Accordingly, while men seeking promotion to managerial level simply exhibit appropriate desired behaviors, women 
must 'first break that passive image of women holding diminutive power in a male-dominated domain' which can be remarkably challenging if the organization is lacking female role-models and organizational support (Eagly 2009).

An overview of the glass ceiling (GC)

Glass ceiling was initially described as a perception or experience of women in the domain of business. The first writer to use the metaphor "glass ceiling" was Marilyn Loden in 1978 and it was later popularized at a Conference of the Women's Institute for Freedom of the Press led by Katherine Lawrence in July 1979 (Fernandez 2011; BusinessNews Publishing 2013). The conventional use of the word "glass ceiling," according to the Oxford English Dictionary and most of the conserved narratives on and off the web is illustrated in a remark in the American Magazine World/Adweek in 1984 (Morgan 2015). A much more recent account of glass ceiling phenomenon originated in a Wall Street Journal report on corporate women by Hymowitz and Schellhardt in 1986. Essentially, glass ceiling connote a barriers encountered by women who endeavor, or desire, to occupy senior positions (as well as higher salary ranks) in establishments such as corporate organizations, government entity, and nonprofit organizations among others (McCarthy and Burns 2013).

In general, women's under-representation in top leadership position has been regarded as a barrier that is holding women back from attaining managerial position in the workplace. Women in the executive position may also experience the metaphors like "glass elevators" and "glass cliffs" which represent greater scrutiny and condemnation (Ryan and Haslam 2005). Further expression such as "sticky floors" was coined by Catherine Berheide's in 1992 to describe the circumstances where women and men having almost equal capabilities are employed to the same level or positions; but more often than not, appointment of the women is 
prevalent at the lower hierarchy and men are promoted to higher level (Erik and Marita 2006). Descriptions such as "perspex ceiling," "sticky cobweb," "labyrinth" and "greasy pole" among others have also been operationalized to represent glass ceiling phenomenon in gender and diversity management literature. However, irrespective of the metaphor adapted to describe glass ceiling, one thing that is common to glass ceiling representation is that women opportunities to progress along their career path disappear at various points along the route of their career development.

According to Ying et al. (2011), three key restrictions fuel glass-ceiling occurrence: customary gender roles, expressions of sexism in the workplace, and lack of sponsorships. Janeen and Erik (2000) maintain that two things must prevail to demonstrate and prove the existence of glass ceiling: (1) the proportion of women compared to men being promoted into or entering a given cadre of management drops as they move up the managerial hierarchy and (2) that this decline in comparative progression will likely decline further and deepened the hurdles of women promotion as opposed to some other factors. Kantor (1977) noted that a number project based studies on glass ceiling were founded on a faulty analysis. For instance, those who presumed that the elements creating inequalities in workplace are some how conceded in the individual are relying on the wrong model to draw erroneous conclusions. Such level of analysis according to her, anticipated that such disparities were due to either nature or nurture: that's women were not the same as men by nature (so they were not so struggling or competitive), or women were fostered in a different way from men (hence, they are constrained not to be competitive or occupy positions of leadership).

Eagly and Carli (2007) further contended the exactness of the "glass ceiling," and argued that it suggests systematic upward movement that is then obscenely thwarted by an ambiguous 
hurdle that obstructs further progression. These scholars further posit that, GC is not one ceiling or partition in one spot, but rather numerous and ubiquitous forms of gender prejudice that are multifaceted and occur in both obvious and hidden ways. Wright (1997) observes that the "glass ceiling" appears to be established by casual observation, because it does not require logical research to notice that a much higher proportion of bottom supervisors other than Chief Executive Officers are women. According to Rai and Srivastava (2008), glass ceiling is a relative term; hence, it does not exists, because women receive lower salaries due to career disruption, worked for lesser time and engaged in low-risk jobs. David et al. (2001) contend that if glass ceiling is proposed purely as a gender or any other form of inequalities, then researchers and advocacy of gender equality are merely promoting the concept to simplify communication in the public domain, which do little or no impact on effort to determine the root causes of inequality.

Perspectives on glass ceiling barriers

Women have occupied leadership positions both in business and other field of human endeavors. Nevertheless, in almost all situations, male leaders significantly outnumber female and the latter have made very few inroads into senior managerial positions (Ann et al. 2015). Barriers in the workplace can be viewed from two distinct perspectives: formal versus informal barriers, where formal denotes biased government policy or rules, and informal about cognitive and cultural barriers. Barreto, Michelle, and Micheal (2009) posit that the notion of glass ceiling is a symbolic obstacle which can be detached from formal or legitimate barriers to career advancement such as level of education or work experience. According to Fagenson (1990), women's progression to leadership position can be influenced by the individual factors within 
the person, organizational factors which are situated within the organization, and societal and systemic factors.

In some settings, particularly patriarchal societies, there are arrangements controlling the roles of women, making the under-representation of women in executive positions acceptable norms (Kulkarni 2002). In general, traditions and laws against female leadership can be found throughout human history, most remarkably in every major religion (Christ 2014). For instance, right from the childhood, women are compelled to obey some social rubrics which are firmly enrooted in their mind and as such they find it difficult to ignore the influence of those rules when they matured (Kulkarni 2002). These traditional and cultural inhibitions according to the scholar are further fostered by parents and duly strengthened by socialization. Correspondingly, society has consciously upheld the convention that a woman's ideal place is at home (Jacobs 1992) and this has promoted some practices that exceptionally violate their constitutional rights. For instance, in some tribal/ethnic group in Nigeria women need to contend with many oppressive and discriminatory cultural practices such as: right of women to inheritance, marriage dissolution, widowhood practices, and Son-preference syndrome among others (Babatunde 2014; Ifemeje and Umejiaku 2014).

Likewise, barriers from the family tend to be more multifaceted and exert serious interruption on women's career paths than those of men which are characteristically trajectory, and this obstructs women's progression to top leadership positions (Cansu 2013). As observed Spector et al. (2004), family related complication and glass ceiling hurdles in the workplace could also be linked to culture. For instance, in Anglo based cultures, research has shown that elongated working hours is not connected to work-family stress and productivity. Possible reason for this could be that in these cultures, dual income families and partners are more supportive of each 
other's career ambitions. In contrast, in Western culture, 'male breadwinner' notion is still common, relegating the significance of a wife's career. Accordingly, these forms of conception and associated demands create difficulty for career advancement of women and the degree of their career growth. Notably, women often have to deal with the complications of the numerous roles played by them in the family and at work and in many instances they have to make sacrifices, prioritizing family demand over work life which further slows down their careers progression (Sarika 2015).

According to Siew and Geraint (2012), institutional barriers have also been documented to propel occupational segregation (i.e. gender-based employment discrimination) which works against the interest of women. According to these scholars, the discrimination may arise from horizontal or vertical dimensions. The horizontal discrimination echoes the fact that men and women are assigned differently across occupations while vertical segregation defines how men and women work in different status of occupations (Siew and Geraint 2012). As observed by the European Commission's Expert Group on Gender and Employment-EGGE (2009), horizontal discrimination is based on under-(over) representation of a given group in occupations or a sector, not founded on any criterion, and is often denoted to as segregation "tout court". Vertical segregation on the other, represents the under (over) representation of a noticeably recognize group of employees in a particular jobs or industry at the topmost based on 'desirable' characteristics such as income, prestige, job stability etc., independently of the sector or activity. Anne and Elke (2011) maintained that vertical segregation indicates the presence of observable or obscure hindrances that lead to certain fewness of women in top rank positions in organization. 
As regard individual barriers, a number of psycho-social attributes, such as self-esteem, self efficacy, assertiveness, emotional stability, sense of perceived control, optimism and inclination towards social relationship are somewhat weakly exhibited by women's due to some of the aforementioned reasons (Sarika 2015). The research carried out by Wirth (2001) added to the debate surrounding glass ceiling conundrum. He reported that the "dissimilar career desires" of women prompt them to create a self-inflicted glass ceiling, deceptively considering that a glass ceiling would hinder their careers. For instance, women exert struggle to maintain balance between her motherhood and her career progression (Koshal, Koshal, and Gupta 2006). In addition, effective management control/rewards system, boldness, aggressiveness and autonomy, have largely been acknowledged as "masculine" personality (Sarmistha, Arnab, and Sovonjit 2014). In addition, the challenges to the barrier women's experience are further complemented by lack of self-direction, independence of mind and poor self-motivation (Kulkarni 2002). Remarkably, it has also been reported than most women are less ambitious and this hinders their opportunity to climb the career ladder (Ann et al. 2010). Although the impression that women are not concerned about their elevation to high managerial positions due to the challenges of work life balance has been widely criticized (Cansu 2013).

Accoding to Morgan (2015), organizational barriers stimulated the structure beyond a single or primary dependence upon individuals and their work relations (the "attitudinal" components) towards organizational, systemic, or obstructions within which individuals acted. For instance, in many corporate organizations, gender stereotyping is very pervasive and this has become a kind of structural norms which further encourage double standard in term of administrative policy and rules that encourage glass ceiling. As a result, men in positions of authority are hesitant to recommend women to top managerial position for fear of their emotions, and the 
perceived idea that they will often take time off job to cater for their family (Sarmistha, Arnab, and Sovonjit 2014). Ironically, in a situation a woman is exceptionally self-confident and stands out as a potential leader, the prevailing masculine corporate culture is yet another obstacle for their career growth (Eagly and Carli 2007). Likewise, men in position of authority feel threatened when there is a strong independent minded woman executive in the board room and they often try to heckle intentionally and create barriers in several form to prevent their upward mobility in the organization (Sarika 2015).

The glass ceiling conundrum and sponsorship effects

Desire for career progression and success for both men and women is a fact of life. Simply, because everybody wants to see their capabilities and skills recognized and rewarded. Therefore, in accomplishing meaningful career life, building sponsorship has become something of a struggle that promotes powerful coalitions across corporate ladder. A study conducted by Ann et al. (2010) revealed that among the numerous paths to authority, sponsorship is underestimated — and thus, underutilized — by both men and women. According to their study, relatively, men are reaping the benefits of the old-boy networks, but women need to avail themselves of every benefit, every alternative pathway to the top echelons of power through improves sponsorship. Ann et al. (2010) further observe that women's lack of enthusiasm to actively seek sponsorship is amply justified. According to them, the deeper the ally of women to senior executive becomes the more the speculation that the relationship is more than professional.

In recent times, academics and business practitioners have focused on sponsorship, as a form of mentorship in which sponsors acquired both status and opportunity. However, a sponsor is not to be mixed up with a mentor. Although a leader can be both a mentor and a sponsor, 
however, the roles are distinctive (Ann et al. 2010). A sponsor in the opinion of these authors sticks their neck out visibly towards their protégée performance and career progression. In contrast, they declare that it is possible to mentor and coach someone who is unpleasant without risking ones reputation, because mentorship can be done behind the scene. According to Ann et al. (2010), the dynamic force in a mentorship lies with the mentee, whereas in sponsorship, it is the sponsor who guides and energies the relationship.

In recognizing the difficulties generated by the glass ceiling, women have to realize that in order to crack it, they need to advocate and support each other in advancement efforts. Ironically, it is disheartening to find out that women feel threatened by their women counterpart and more often they are the major critics and impediments to other women (Jones 2014). This scenario is referred to as "queen bee syndrome" in management literature relating to what women experience while struggling to advance their career in the workplace. According to Wrigley (2002) and Drexler (2013), women in managerial positions tries to sabotage those in lower levels and are unenthusiastic in supporting and assisting other women in lower levels to progress to leadership position. Also, given the disparity of women at the top echelon in the executive positions in the organization, it is equally possible that fewer women executives that make it to the top will join hands with the men to sabotage other female employees in junior cadre of the organizations to engage in severe criticisms that will project them as bad candidates for management position on the ground of envy and to promote the interest of men's club. Jones (2014) further remarks that women also experience confidence problem after securing leadership position. According to him, after fighting arduous battle of career progression for so long, they became battle scares; women tend to be self-condemn, instead of showing confidence 
and appearing assertive. Hence, their inability to fully integrate into board room politics and challenge the status quo of old-boy networks (Jones 2014).

Gender characters and work life balance as a contributing factors to glass ceiling in the workplace

According to Williams (2000), men get preferential treatment whether they are in the majority or minority, while women are disfavored, particularly, if they are in the minority, and occasionally even when they belong to the majority. Working women aside from their job career manage home affairs, which exemplifies a vital and associated social change (Kirkton and Greene 2000). More worrisome is the fact that even if a female executive struggle and break the glass ceiling, often time they find themselves trapped in a secondary form of glass ceiling "glass cliff”, which is more precarious (Douglas and Porcher 2012). In other words, women executive experience a gendered dual dilemma, for instance, if women's is excessively self-confident and masculine she may be perceived as competent but not friendly and if her behavior is too womanly, she may be seen as pleasant but inept (Eagly and Carli 2007).

Furthermore, women that managed to shatter the glass ceiling are subjected to intense scrutiny than men and must overcome a complex tavern on a number of other issues such as sexual harassment, being labeled as arrogant and unsociable etc. (Heilman et al. 1998). For instance, women must exhibit "executive posture" in their dress and manner, and if they go awry, is an opportunity to label them with bad names that may disqualify them for executive positions. Similarly, women must navigate ordeal of unexpressed verdicts with regard to their personal life to climb managerial positions, and may be compelled to acquire male attitudes to scale through the hurdles (Eagly and Carli 2007). In addition, instances abound in some organizations that prevented women from getting married or pregnant for some period of years and when this 
is violated they are dismissed from their jobs but the men who impregnated them keep their jobs. In other words, there's a sharp difference in what men sacrifice compares to what women give up to whither the challenges associated with their career progression (Babatunde 2012). Arguably, work-life balance is imperative in accomplishing a flourishing career, hence, with enlarge responsibilities in the work place, the boundary between work life and private life require additional realization (Fapohunda 2014). According to Clark (2000), work life balance is the level of fulfillment and well-meaning functioning at work and at home, with the smallest level of role conflict. As observes by Fapohunda (2014), employee that experience happy home tend to experience pleasant work life; on the contrary, where employees are unable to properly balance work and family life, they tend to find it difficult to manage tasks at the workplace and this subsequently shrinks productivity. The popular phrase in management literature "Do we live to work or we work to live? Has succinctly captured the concern and value of how and what individual place on work and home (or family) and the two domains represent the most important aspects in the life of a working individual (Greenhaus, Collins, and Shaw 2003).

For women employees the day is not over when they close from office, because another set of work starts at home. This is the reality most married women unavoidably assumed when they get home. Perhaps, nature and cultural belief has bestowed on them the role of a wife and a mother. Hence, the challenges of balancing work and family for women is particularly challenging and will continue to be a fundamental concern for both individuals and organizations (Valcour 2007). Remarkably, work-life balance challenges can influence women's advancement and, if not proactively handled may trigger glass-ceiling phenomenon. Generally, women are the prime family caregivers for children and/or the aged, which further handicapped many to make move that would increase the prospect of progressing up the 
corporate hierarchy. Similarly, prospects for promotion often place men at advantage due to evolving privilege, arising from mentoring and networking; which their women counterparts may not have the benefit to build, thus, contributing to gender obstacles in the workplace (Ann et al. 2010).

\section{Discussion}

It is becoming a usual convention to ascribe the position of Chief Executive Officer or Managing Director to male, not female, because the position is male dominated. Similarly, it has become a recurring phenomenon, that women are able to progress marginally in corporate leadership ladder, before stumbling on a 'glass ceiling' that inhibits or decreases their prospect of reaching top executive status. In some sector, the phenomenon of glass ceiling is made of something much tougher to crack, hence, instead of breaking the glass ceiling; women have only succeeded to chip away at its surface. While the causes of glass ceiling are questionable, its impacts are very feasible and undeniable and the biases experience by women is readily obvious, however, the mechanisms underlying these prejudices remain impervious. This paper reveals that despite some promising improvements, gender inequality remains in the workplace and increasing gender equality in educational and work experience attainment does not stop women from being concentrated in middle to lower-paid occupations that echo traditional gender stereotypes and opinions about women's and men's ambitions and capabilities (ILO 2015). The reality is that in theory, nothing stops women from rising to the top position in their chosen career as men do. However, in practice there exist obscure barriers through which the advancement of women to top rank position is restricted.

Across the globe, discrimination in any form in the workplace is prohibited, yet it exists in numerous facets such as inequitable earning, recruitment practices, and promotional 
opportunities among others which are mostly in favor of men for comparable positions in similar establishments. The glass ceiling conundrum is manifested in various ways: such as cultural and family induced issues (i.e., gender roles ethnicity, work life balance, and religious discrimination in the workplace). Glass ceiling has also been observed to emanate from individual factors such as subjective personal obstacles - passion for long term goal, pessimistic view, perseverance, degree of life satisfaction, and unpleasant affect among others (Powell and Butterfield 2003). Correspondingly, numerous organizational induced factors have also been documented to obstruct the progression of women to senior positions such as lack of familyfriendly workplace policies (Acker 2006), human capital obstacles (lower educational qualification, access to financial resources, and cognate experience); marginalization from informal networks; weak sponsorship, inadequate management support for work/life programs; absence of mentors and role-models; and attitudinal and organizational prejudices (Bombuwela and De Alwis 2013).

More importantly, women also experience some form of role conflict between work and family demand which further affect their productivity and consideration for top managerial positions. In particular, research has revealed that one of the major dissimilarities between men and women are their capabilities to network. For instance, sponsor opportunity is more readily and easily accessible by men compare to women. Ann et al. (2010) claimed that women progression to management position remain far outnumbered by male executives because they lack the influential sponsorship required to motivate, drive, and safeguard them through the terrifying channels of what is require to occupy leadership position. Besides, even if women executives possess requisite qualification, competence, and zeal to progress in their careers, very few lucky 
ones attain the same status as their male counterparts, for the sake of the so-called 'glass ceiling' (Eagly and Carli 2002).

\section{Conclusion and implications}

This paper reviews the glass ceiling conundrum as a form of oppressive tendency that limits women's career advancement in the workplace. From a rational point of view, women have the skills and competence to lead; the missing link is perhaps the inadequacy of the needed support to encourage, drive, and safeguard them through the terrifying canals of leadership position. Put differently, it is not that women completely lack the knowledge and capability to progress to upper management levels, but at some point they are prevented by invisible barriers that block them from rising further to top executive cadre. This suggests that the impediments women experience compare to men steadily increase as they move up to the top hierarchy due to cultural bias, religion sentiment, individual and organizational factors. It has also been widely admitted that the traditional male-controlled policy and practices are slow to adjust to contemporary realities and may transpire slowly (Bramham 1991); consequently, progressive societal and organizational reorientation are critical to challenge the prevailing beliefs, ethos, and authority relationships to change perceived male dominance in the workplace. For that reason, it appears necessary to advance exceptional campaigns action to increase women's representation in top echelon of organization. Likewise, most firms have been hooked to the generalized sense of the dictum of the traditional roles of women (house wife), which further aggravates discrimination of women in the workplace. Furthermore, the struggle that women confront to advance to the top of their career cannot be entirely attributed neither to male conspiracy nor domestic responsibilities, but inadequate support and poor advocacy. 
This paper identified specific behaviors and workplace practices that fuel glass ceiling at work and it has offered ample evidences that revealed how female employees are discriminated against in the workplace. In particular, the authors noted that inequality between men and women continues in global labor markets, in respect of opportunities, behavior and consequences. Furthermore, the paper offer a depiction of where women stand today and how they have advanced in the domain of work and more importantly the root causes of disparities and how they should be addressed based on what is feasible and sustainable. The impending factors that propelled discrimination in the workplace need to be address by ensuring on one hand, strict compliance of corporate organization to the contemporary human resource management policy and practices and on the other hand, there is need to advocate and propelled the needed strategies that will advance women progression in the workplace.

\section{Recommendations}

This paper offers the following recommendations.

1. Women's under-representation in executive position will not upsurge significantly without major changes in the culture, policies, and practices of the organizations where women learn and work. Therefore, there is need to endorsed policy framework that promote strong organizational culture that create a more helpful and supportive environment, adaptive workplace policies, and practices, and capacity building to develop women confidence level required for occupying top executive positions.

2. The notion of glass ceiling needs to be approached with fairness and equity in ensuring that individuals that bring the same capabilities to work (qualifications, knowledge and abilities), or accomplish the same task(s), get the same opportunity to advance their career regardless of gender, race or any other prejudice factors. This will provide avenue for 
women to move from the sidelines to the mainstream of executive cadres, and by extension their willingness to collaborate and offers their best to organizational growth.

3. Likewise, effort should be made to communicate and emphasis continuing obligation to workforce diversity throughout the organization with a view of removing artificial barriers at every level so as to promote feminist-based organizational transformation which is the latest management fad of advocating gender equity, ethical behavior and friendly/supportive organizational climate.

4. Although numerous descriptions have been advanced about what obstructs women career advancement in the workplace; in adequate sponsorship is one of the most prevalent factors that inhibit women from attaining top leadership positions. Therefore, there is need to make one-on-one relationships between sponsors and protégés "secure" and "transparent" to safeguard sponsorship opportunity for women competing for executive positions. The approach may also include promoting policy that sanctions mentors if their mentees are not promoted to the board within a certain period of time.

\section{Limitations and suggestion for further studies}

The major drawbacks associated with this paper is the adoption of literature review approach which raises the likelihood of accommodating similar research paradigms or views of the previous studies that were not empirically validated and may reflect a common methodology bias. Nonetheless, the adoption of survey approach (through questionnaire) has been documented to be inadequate for measuring phenomenon such as glass ceiling (Mohammadkhani and Dariush 2016). However, there is an important gap that needs to be filled, which requires further research attention. Such research inquiry could adopt qualitative research approach specifically 'face to face interview' to unravel and deepen research effort 
aiming at identifying the various forms of barriers women encounter in the workplace, and how to proffer solution to the menace of glass ceiling in the workplace. Also, given the prominence of glass ceiling in the workplace, there is potential for future research into why significant improvement of women into top managerial position remains a mirage. Therefore, an important research inquiry is to investigate glass ceiling from a broader point of view that encompasses the opinion of government, community leaders', religious leaders, and internal customers among others. Obviously, different strata of the society will have different opinions and it is natural such diverse approach will offer diverse points of view that could provide useful insights as well as offering a more realistic approach to strengthen women representation in top management position and to ensure their full capacity development.

\section{References}

Acker, Joan. 2006. "Inequality regimes, gender, class, and race in organizations." Gender and Society 20: 441-464.

Adler, Nancy J. 1993. "Cross cultural management: Issues to be faced." International Studies of Management and Organization 13 (1/2): 7-45.

Babatunde, Akanji. 2012. "Realities of work life balance in Nigeria: Perceptions of role conflict and coping beliefs." Journal of Human and Society 10 (2): 248-263.

Babatunde, Akanji O. 2014. "Discriminatory property inheritance rights under the Yoruba and Igbo customary law in Nigeria: The need for reforms." IOSR Journal of Humanities and Social Science 19 (2): $30-43$

Barreto, Manuella D., Michelle Ryan K., and Micheal Shemitt T. 2009. The glass ceiling in the 21st century: Understanding barriers to gender equality. Washington, DC: American Psychological Association.

Baxter, Janeen, and Erik Wright O. 2000. "The glass ceiling hypothesis: A comparative study of the United States, Sweden, and Australia." Gender and Society 14 (2): 275-294.

Bombuwela, Pon M., and De Alwis Chamaru A. 2013. "Effects of glass ceiling on Women career development in private sector organizations - Case of Sri Lanka." Journal of Competitiveness 5:319. 
Bosse, Douglas, A., and Pocher Taylor III L. 2012. "The second glass ceiling that impede women entrepreneurs." The Journal of Applied Management and Entrepreneurship 17 (1): 52-68.

Bramham, Peter. 1991. "Explanations of the organization of sport in British society." International Review for the Sociology of Sport 26:139-153.

Busch, Anne, and Elke Holst. 2011. "Gender-specific occupational segregation, glass ceiling effects, and earnings in managerial positions: Results of a fixed effects model.” IZA DP No. 5448 January. Discussion Paper No. 5448 January 2011. Accessed January 23, 2017. http://ftp.iza.org/dp5448.pdf

Cansu, Akpinar-Sposite. 2013. "The glass ceiling: Structural, cultural and organizational career barriers for French and Turkish Women executives." Paper presented at the Le 24_eme congress de l'AGRH 2013, Paris, France.

Catalyst. 2015. Women CEOs of the S\&P 500. Accessed January 18, 2016. http://www.catalyst.org/knowledge/ women-ceos-sp-500.

Christ, Carol P. 2014. "Do we still need the journal of feminist studies in religion?" Journal of Feminist Studies in Religion 30 (2): 139-141.

Clark, Sue C. 2000. "Work/family border theory: A new theory of work/family balance." Human Relations 53 (6): 747-770.

Constance, Helfat, Dawn Harris, and Paul Wolfson. 2006. "The pipeline to the top: Women and Men in the top executive ranks of U.S. corporations." Academy of Management Perspectives 20 (4): 4264.

Cotter, David A., Jean Hermsen M., Seth Ovadia, and Reeve Vanneman. 2001. "The glass ceiling effect." Social Forces 80 (2): 655-682.

Daily, Catherine, Dalton Pfeffer, and Albert S. Cannella. 2003. "Corporate governance: Decades of dialogue and data." Academy of Management Journal 28:371-382.

Davidson, Marilyn J., and Burke J. Ronald. 2012. Women in management worldwide: Progress and prospects. Farnham: Gower Publishing.

Drexler, Peggy. 2013. "The tyranny of the Queen Bee." The Wall Street Journal 6 (6): 8. Accessed January 18, 2016. http://www.wsj.com/articles/SB10

Eagly, Alice. 1987. Sex differences in social behavior: A social role interpretation. Hillsdale, NJ: Erlbaum.

Eagly, Alice H. 2009. "The his and hers of prosocial behavior: An examination of the social psychology of gender." American Psychologist 64:644-658.

Eagly, Alice H., and Carli Linda. 2007. Through the Labyrinth: The truth about how women become leader. Boston, MA: Harvard Business School. 
Eagly, Alice H., and Johannesen-Schmidt Mary C. 2001. "The leadership styles of Women and Men." Journal of Social Issues 57:781-797.

Eagly, Alice H., and Karau Steven J. 2002. "Role congruity theory of prejudice toward Female leaders." Psychological Review 109 (3): 573- 598.

Eagly, Alice H., Wood Wendy, and Diekman Amanda B. 2000. "Social role theory of sex differences and similarities: A current appraisal." In The developmental social psychology of gender, edited by Eckes, T. and Trautner H.M., 123-174. Mahwah, NJ: Erlbaum.

Erik, Bihagen, and Marita Ohk. 2006. "The glass ceiling-Where is it? Women's and Men's career prospects in the private vs. the public sector in Sweden 1979-2000.” The Sociological Review 54 (1): 20-47.

European Commission's Expert Group on Gender and Employment-EGGE. 2009. Gender segregation in the labour market root causes, implications and policy responses in the EU. Luxembourg: Publications Office of the European. Union, 2009. Accessed December 13, 2016. httpt://www.ec.europa.eu/social

Fagenson, Ellen A. 1990. "At the heart of the Women in management research: Theoretical and methodological approach and their biases." Journal of Business Ethics 9:267-274.

Fapohunda, Tinuke M. 2014. "An exploration of the effects of work life balance on productivity." Journal of Human Resources Management and Labor Studies 2 (2): 71-89.

Fernandez, Marilyn L. 2011. On feminine leadership. Pelican Bay Post, May.

Fondas, Nanette. 1997. "Feminization unveiled: Management qualities in contemporary writings." Academy of Management Review 22:257-282.

Ganiyu, Rahim Ajao, Dixxon-Ogbechi Bolajoko N., and Salome Ighomereho O. 2013. "Gender and relationship marketing in Nigerian securities and stock brokerage firms." International journal of Marketing Studies 5 (4): 72-81.

George, Dreher F. 2003. "Breaking the glass ceiling: The effects of sex ratios and work-life programs on Female leadership at the top." Human relations 56 (5): 541-562.

Goldstar Directories. 2007. Nigeria's top 500 companies. Lagos: National Directories Division of Goldstar Group.

Greenhaus, Jeffrey H., Karen M. Collins, and Jason D. Shaw. 2003. "The relation between work-family roles." Academy of Management Review 10 (1): 76-88.

Gupta, Ashok, Manjulika Koshal, and Rajindar K. Koshal. 2006. "Women managers in India: Challenges and opportunities." In Management in India: Trends and transition, edited by Herbert J. Davis, Samir R. Chatterjee, and Mark Heuer. New Delhi: Response Books. 
Hassim, Shireen. 2009. Rethinking gender politics in a liberal age: Institutions, constituencies and equality in comparative perspective, UNRISD. Accessed March 23, 2017. http://www.unrisd.org

Heilman, Madeline E., Block Caryn J., Martell Richard F., and Simon Micheal C. 1998. "Has anything changed? Current characterizations of Men, Women and managers." Journal of Applied Psychology 74:935-942.

Hewlett, Ann, Kerrie Peraino, Laura Sherbin, and Karen Sumberg. 2010. "The sponsor effect: Breaking through the last glass ceiling." Center for Work-Life Policy, Harvard Business Review, December.

Hiau, Kee J. 2008. "Glass ceiling or sticky floor: Exploring the Australian gender pay gap." The Economic Record 82 (59): 408-427.

Hiau, Kee J. 2005. "Glass ceiling or sticky floor? Exploring the Australian gender pay gap using quantile regression and counterfactual decomposition methods." Discussion Paper No. 487, The Australian National University Centre for Economic Policy Research.

Hymowitz, Carol, and Timothy D. Schellhardt. 1986. "The glass-ceiling: Why Women can't seems to break the invisible barrier that blocks them from top jobs." The Wall Street Journal, March 24.

Ifemeje, Sylvia C., and Umejiaku Nneka. 2014. "Discriminatory cultural practices and Women's rights among the Igbos of South-East Nigeria: A critique." Journal of Law, Policy and Globalization 25: $18-27$

International Labor Organization. 2015. Women at work trends 2016. Geneva: International Labor Office. Accessed January 13, 2017. http://www.lopubs@ilo.org.

Jacobs, Jerry A. 1992. "Women's entry into management: Trends in earnings, authority, and values among salaried managers." Administrative Science Quarterly 37 (2): 282-301.

Jain, Neera M., and Mukherji Shoma. 2010. "The perception of 'glass ceiling' in Indian organization: An exploratory study." South Asian Journal of Management 17 (1): 23-42.

Janeen, Baxter, and Erik Wright O. 2000. "The glass ceiling hypothesis: A comparative study of the United States, Sweden, and Australia.” Gender and Society 14 (2): 275-294.

Jasielska, Aleksandra. 2014. "Women career success in a Man work's place: A cross national study." Romanian Journal of Experimental Applied Psychology 5 (1): 23.

Jerlando, Jackson F.L., and Elizabeth M. O’Challagham. 2009. "What do we know about glass ceiling effects? A taxonomy and critical review to inform higher education research." Research High Education 50:460-482.

Jones, Beverly. 2014. "Boomer Women hit the glass ceiling. Four tips to crack it now." Forbes. Accessed January 13, 2017.om http://www.forbes.com/sites/nextavenue/2014/10/10/boomerwomen-hit-the-glass-ceiling-four-tips-to-crack-it-now/. 
Kantor, Roseabeth M. 1977. Men and Women of the corporation. New York: Basic Books.

Kirkton, Gill, and Anne-Marie Greene. 2000. The dynamics of managing diversity: A critical approach. Oxford: Butterworth Heineman.

Kolade, John O., and Kehinde Obasan. 2013. "Glass ceiling and women career advancement: Evidence from Nigerian construction industry." Iranian Journal of Management Studies 6 (6-1): 77-97.

Kunze, Astrid. 2008. "Gender wage gap studies: Consistency and decomposition.” Empirical Economics 35:63-76.

Kulkarni, S. Sushma. 2002. "Women and professional competency - A survey report." Indian Journal of Training and Development 32 (2): 11-16.

Laermer, Richard and Michael Prichinello. 2013. Summary full frontal PR. Review and analysis of Laermer and Prichinello's Book. Business News Publishing.

Lombardo, Emanuela, and Meier Petra. 2006. "Gender mainstreaming in the EU: Incorporating a feminist reading?" European Journal of Women's Studies 13:151-166.

McCarthy, Kelly, and Paula Burns. 2013. The double glass ceiling: An in-depth investigation and analysis into the challenges faced by Women when seeking promotion to the boardroom and beyond the executive suite. A BPP Business School Working Paper - December. Accessed January 13, 2017. http://www.Bpp.Com

Meyerson, Debra E., and Joyce K. Fletcher 2000. "A modest manifesto for shattering the glass ceiling." Harvard Business Review 1 (1): 127-140.

Mohammadkhani, Fatemah, and Dariush Gholamzadeh. 2016. "The influence of leadership styles on the Women's glass ceiling beliefs." Journal of Advanced Management Science 4 (4): 276-282.

Mordi, Chima, Ruth Simpson, Singh Satwinder, and Okafor Chinonye. 2010. "Motivation to be a Female entrepreneur in Sub-Saharan Africa." Gender in Management- An International Journal 25: 5-25.

Morgan, Mary S. 2015. "Glass ceilings and sticky floors: Drawing new ontologies.” Working Paper No. 228 (December). London School of Economics and Political Science, Department of Economic History.

Morrison, Ann M., White Ramdall P., and Von-Velsor Ellen. 1987. Breaking the glass ceiling: Can Women reach the top of America's largest corporations? Reading, MA: Addison-Wesley.

Powell, Gray N., and Anthony D. Butterfield. 2003. "Gender, gender identity, and aspirations to top management." Women in Management Review 18 (1/2): 88-96.

Rai, Usha K., and Monica Srivastava. 2008. "Women executives and the glass ceiling: Myths and mysteries from Razia Sultana to Hillary Clinton.” BHU Management Review 1 (2):79.

Ridgeway, Cecilia L. 2001. “Gender, status and leadership.” Journal of Social Issues 57 (4): 637-655. 
Rudman, Laurie A., and Peter Glick. 2001. "Prescriptive gender stereotypes and backlash toward agentic Women.” Journal of Social Issues 57:743-762.

Ryan, Michelle K., and Alexander S. Haslam. 2005. "The glass cliff: Evidence that Women are overrepresented in precarious leadership positions." British Journal of Management 16:81-90.

Sarika, Seshadri G. 2015. "Breaking the glass ceiling: Initiatives of Indian industry: A study with special reference to exemplary organizations." The International Journal of Business and Management 3 (3): $255-260$.

Sarmistha, Nandy, Arnab Bhaskar, and Sovonjit Ghosh. 2014. "Corporate glass ceiling: An impact on Indian Women employees." International Journal of Management and International Business Studies 4 (2): 135-140.

Saul, Estrin, Stephan Ute, and Suncica Vujic. 2014. Do Women earn less even as social entrepreneurs? Discussion Paper No. IZA DP No. 8650, 1-47. Institute for the Study of Labor, Germany.

Schein, Virginia E. 2007. "Women in management: Reflections and projection." Women in Management Review 22 (1): 6-18.

Siew, Ching, and Geraint Johnes. 2012. "Revisiting the impact of occupational segregation on the gender earnings gap in Malaysia." Journal of Economi Malaysia 46 (1): 13-25.

Singh, Vall, and Susan Vinnicombe. 2004. "Why so few Women directors in top UK boardrooms? Evidence and theoretical explanations." Corporate Governance 12 (4): 479-488.

Spector, Paul E., Carry L. Cooper, Steven Poelmans, Tammy D. Allen, Micheal P. O'Driscoll, Juan I. Sanchez, Oi L. Siu. 2004. "A cross-national comparative study of work-family stressors, working hours and well-being: China and Latin America versus the Anglo World." Personnel Psychology 57 (1): 119-142.

The American Association of University Women- AAUW. 2016. Barriers and bias: The status of Women in leadership. Accessed January 13, 2016. http://www.aauw.org

Valcour, Monique. 2007. "Work-based resources as moderators of the relationship between work hours and satisfaction with work-family balance." Journal of Applied Psychology 92 (6): 1512-23.

Williams, Christine L. 2000. Unbending gender. Oxford, England: Oxford University Press.

Wirth, Linda. 2001. Breaking through the glass ceiling-Women in management. Geneva: International Labor Office. Accessed January - March 23, 2017.

http://ecampus.nmit.ac.nz/moodle/file.php/4599/Diversity/ILO_Breaking_through_the_Glass_ Ceiling_women_in_management_full_2001.pdf

Wright, Erik O. 1997. Class counts. Cambridge, UK: Cambridge University Press. 


\section{Journal of Evolutionary Studies in Business}

Wrigley, Brenda J. 2002. "What glass ceiling? A qualitative study of how Women view the glass ceiling in public relations and communications management." Journal of Public Relations Research 14 (1): 27-55.

Ying, Zhuge, Joyce Kaufman, Diane M. Sineone, Herbert Chen, and Omaida Velazguez. 2011. "Is there still a glass ceiling for Women in academic surgery?” Annals of Surgery 253 (4): 637-643.

This is an Open Access article distributed under the terms of the Creative Commons Attribution-Non-Commercial-No Derivatives License (http://creativecommons.org/licenses/by-nc-nd/4.0/), which permits non-comercial re-use and distribution, provided the original work is properly cited, and is not altered or transformed in any way. 